\title{
Pulmonary veno-occlusive disease in a HIV-infected intravenous drug abuser
}

\author{
R. Escamilla*, C. Hermant*, J. Berjaud*, C. Mazerolles**, X. Daussy*
}

\begin{abstract}
Pulmonary veno-occlusive disease in a HIV-infected intravenous drug abuser. R. Escamilla, C. Hermant, J. Berjaud, C. Mazerolles, X. Daussy. CERS Journals Ltd 1995.

ABSTRACT: Pulmonary veno-occlusive disease (PVOD) is a rare cause of pulmonary hypertension. Its origin remains unknown but in some cases a viral aetiology has been suggested. Recently primary pulmonary hypertension has been increasingly observed in patients with human immunodefiency virus (HIV) infection, but only one case of pulmonary veno-occlusive disease has so far been described.

We report the case of a 27 year old male intravenous drug abuser with HIV infection and pulmonary hypertension. Open lung biopsy led to the diagnosis of pulmonary veno-occlusive disease. This second case of pulmonary veno-occlusive disease raises the question of a relationship between HIV infection and lesions involving the pulmonary veins. However, the pathogenesis of vascular changes remains to be elucidated.
\end{abstract}

Eur Respir J., 1995, 8, 1982-1984.

\author{
* Service de Pneumo-Allergologie, Toulouse, \\ France. ** Service d'Anatomo-Pathologie, \\ Toulouse, France. \\ Correspondence: R. Escamilla \\ Service de Pneumo-Allergologie \\ CHU Purpan \\ 31059 Toulouse Cedex \\ France
}

Keywords: Human immunodeficiency virus

intravenous drug abuser pulmonary veno-occlusive disease

Received: December 141994

Accepted after revision May 201995
Pulmonary veno-occlusive disease (PVOD) is a rare cause of pulmonary hypertension [1]. Recently, PVOD has been reported in a child with human immunodeficiency virus (HIV) infection [2]. Although pulmonary arterial lesions in $\mathrm{HIV}$-infected (HIV+) patients have been well-described, this was the first reported case of PVOD. We report a second case of PVOD in a HIV+ intravenous drug abuser.

\section{Case report}

A 27 year old white male was admitted to our hospital in January 1991 with severe dyspnoea. His medical history was unremarkable except for an 11 year intravenous drug addiction, mainly with heroin. He was asymptomatic until April 1989, when he developed dyspnoea on exertion. The patient was then admitted to an institution for heroin withdrawal and was found to be HIV seropositive. Despite drug cessation, dyspnoea gradually increased and became permanent. Before his admission to our hospital, the patient did not receive any treatment.

Initial examination showed a blood pressure of 110/70 $\mathrm{mmHg}$, a pulse of 100 beats $\cdot \mathrm{min}^{-1}$ and a temperature of $36.9^{\circ} \mathrm{C}$. Chest auscultation revealed bilateral rales over the lower half of both lung fields. Cardiac examination revealed a loud $\mathrm{P} 2$, a grade $3 / 6$ holosystolic murmur compatible with tricuspid regurgitation, and a right ventricular heave. The liver was not palpable and there was no peripheral oedema. The electrocardiogram showed sinus tachycardia, right axis deviation and right ventricular hypertrophy. Chest roentgenogram demonstrated pulmonary arterial enlargement, Kerley B lines and moderate perihilar interstitial infiltrates (fig. 1).

Laboratory findings were as follows: haemogloblin 11.6 $\mathrm{g} \cdot \mathrm{dL}^{-1}$; haematocrit $34 \%$; leucocytes 5,200 cells $\cdot \mathrm{mm}^{-3}$ (5.2 cells $\left.\times 10^{9} \cdot \mathrm{L}^{-1}\right)$, with $82 \%$ neutrophils and $11 \%$ lymphocytes; T-helper 360 cells $\cdot \mathrm{mm}^{-3}\left(0.36 \times 10^{9} \cdot \mathrm{L}^{-1}\right)$. On room air, arterial oxygen tension $\left(\mathrm{Pa}_{2} \mathrm{O}_{2}\right)$ was $8.0 \mathrm{kPa}(60$

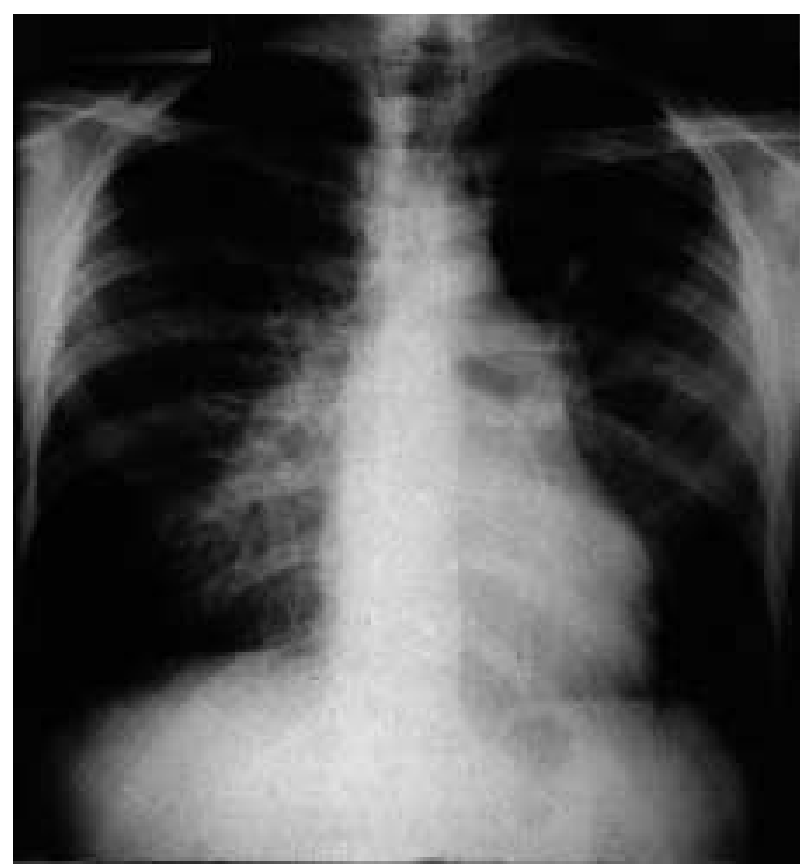

Fig. 1. - Chest roentgenogram demonstrating prominent main pulmonary arteries and moderate perihilar interstitial infiltrates. 
$\mathrm{mmHg})$, arterial carbon dioxide tension $\left(\mathrm{Pa}_{1}, \mathrm{CO}_{2}\right)$ was 4.4 $\mathrm{kPa}(33 \mathrm{mmHg})$ and $\mathrm{pH}$ was 7.43. Pulmonary function tests showed: vital capacity (VC) $4.13 \mathrm{~L}$ (68\% of predicted); forced expiratory volume in one second (FEV1) $2.97 \mathrm{~L}$ (60\% pred); total lung capacity (TLC) $6.6 \mathrm{~L}$ (85\% pred); and transfer factor of the lungs for carbon monoxide $(T \mathrm{~L}, \mathrm{CO}) 14.3 \mathrm{~mL} \cdot \mathrm{min}^{-1} \cdot \mathrm{mmHg}^{-1}(60 \%$ pred $)$. Lung perfusion scan was normal. Pulsed Doppler echocardiography revealed enlarged right atria and ventricle with paradoxical septal motion and tricuspid regurgitation. Right heart catheterization showed a pulmonary artery pressure of $80 / 42 \mathrm{mmHg}$ with pulmonary capillary wedge of $10 \mathrm{mmHg}$ and calculated pulmonary resistance of 726 dyn $\cdot \mathrm{s} \cdot \mathrm{cm}^{-5}$. Fibreoptic bronchoscopy was normal. Bronchoalveolar lavage revealed $86 \%$ macrophages $(40 \%$ of which were haemosiderin laden), 5\% neutrophils, $6 \%$ lymphocytes and $3 \%$ eosinophils. Culture and microbiological examination of the fluid were negative.

Open lung biopsy was performed for diagnostic purpose. Pathological examination demonstrated haemosiderosis varying from mild to quite severe, with some accumulation of macrophages full of iron pigment and with iron encrustation of vascular elastic membranes elsewhere. Muscular pulmonary arteries showed severe medial hypertrophy with muscularization of arterioles. In some, there was intimal fibrosis, mild to rather severe. Occasionally a talcum powder particle was lying within such an intimal thickening, while there was also an occasional foreign body giant cell. Plexogenic lesions were not found. Pulmonary veins and venules showed extensive and often obliterating intimal fibrosis, sometimes with recanalization channels (fig. 2).

These pathological findings established the diagnosis of pulmonary veno-occlusive disease. There was additional foreign body embolism with granuloma formation. The latter factor might be contributing to pulmonary hypertension but PVOD was the main cause.

Prednisone therapy (methylprednisolone $1 \mathrm{mg} \cdot \mathrm{kg}^{-1}$ daily for 1 week, and then $0.5 \mathrm{mg} \cdot \mathrm{kg}^{-1}$ daily for $1 \mathrm{month}$ ) was initiated, with marked improvement of symptoms and interstitial infiltrates. Oxygen therapy was required for 5 weeks. Despite the functional recovery, no improvement of pulmonary hypertension could be demonstrated by pulsed Doppler echocardiography. The patient died sud-

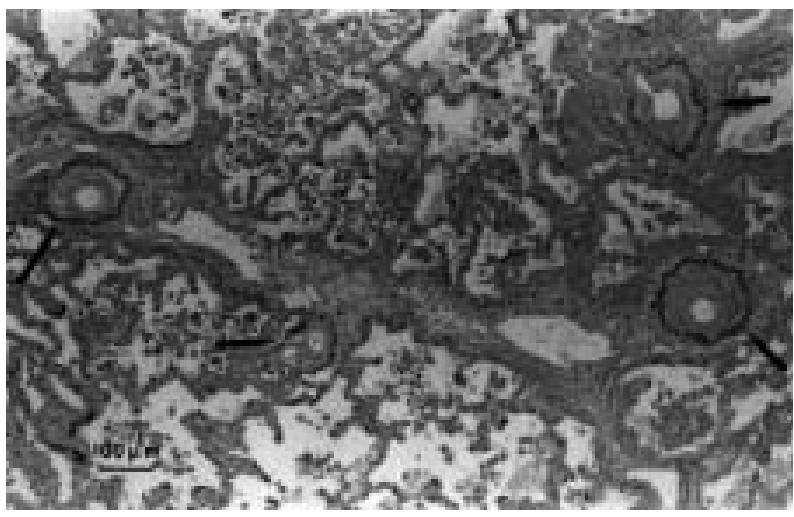

Fig. 2. - Open lung biopsy. Pulmonary veins and venules (arrows) showing extensive and obliterating intimal fibrosis. (Elastic stain; Internal scale bar $100 \mu \mathrm{m}$. Original magnification $\times 100)$. denly at home 6 months later. Autopsy was not performed. Discussion

PVOD is a rare cause of pulmonary hypertension; its aetiology remain unknown but in some cases a viral origin has been considered [1]. Recently, Ruchelli et al. [2] described a 2 year old child with acquired immune deficiency syndrome (AIDS) in whom PVOD was diagnosed at autopsy, and suggested that this association might not be coincidental. Our case in an intravenous drug addict (IVDA) with HIV infection also suggests a possible relationship between these two pathologies.

Respiratory infection (especially viral infection) or immunological disorders with the presence of immune complexes which have been suggested as PVOD aetiological agents, were not demonstrated in our patient nor had he never received chemotherapeutic agents.

A role of drug addiction should also be considered. In fact, pulmonary vascular lesions related to drug addiction have been well-documented [3]. The most common finding was an extensive arterial thrombosis due to foreign particle embolisms, with granuloma formation. However, significant vascular changes were observed exclusively in association with numerous embolized foreign bodies. Lesions involving the pulmonary veins were not described. Although foreign bodies were occasionally found in our patient and probably had had some minor participation in arterial damage, PVOD, which might itself involve the pulmonary arteries [4], represented the main cause of pulmonary hypertension.

Moreover, because of the increased frequency of pulmonary hypertension in HIV+ patients, it has been suggested that HIV might play a role in the development of the vascular lesions observed [5, 6]. Thus, MetTE et al. [7] suggested an indirect role of HIV: the vascular changes might be the result of the release by infected cells of mediators with a proliferative effect on endothelial cells.

Finally, in view of the relative rarity of PVOD, it seems unlikely that the cases reported in association with HIV infection occurred by chance alone [2]. From a clinical point of view, our patient was not affected by opportunistic infections or tumours. In the case previously reported, PVOD occurred before the state of severe immunodeficiency.

In our case, PVOD was not clinically suspected. Most PVOD patients present with dyspnoea, radiographic pulmonary hypertension, and often congestion or oedema. In HIV+ patients, dyspnoea and perihilar infiltrates suggest various pathologies, including tumoral involvement, and nonspecific or lymphoid interstitial pneumonitis [8], which might be misdiagnosed by the bronchoalveolar lavage. In such a situation, despite its inherent risk, open lung biopsy can be useful both to eliminate infectious or tumoral process and to evaluate vascular lesions.

PVOD therapy is controversial. As described previously [9], corticosteroids may lead to a transient improvement in functional status and interstitial pneumonitis but the course of PVOD itself is not affected. Although unsubstantiated, the use of steroids is to be recommended in the absence of current infection because of the poor prog- 
nosis of PVOD. Oral anticoagulation is commonly used to prevent venous thrombosis and pulmonary arterial embolism; however, in drug addicts, caution should be emphasized concerning anticoagulation because of the weak support for therapeutic prescription. Finally, although prostacyclin provides a great advance in the treatment of primary pulmonary hypertension [10], its effectiveness in patients with PVOD is not established.

We conclude that this second case of PVOD in a HIV+ patient suggests a possible relationship between these two pathologies. The pathogenesis remains to be elucidated.

\footnotetext{
Acknowledgements: The authors wish to thank C.A. Wagenvoort for his valuable pathologic examination.
}

\section{References}

1. Wagenvoort CA. Pulmonary veno-occlusive disease: Entity or syndrome? Chest 1976; 69: 82-86.

2. Ruchelli ED, Nojadera G, Rutstein RM, Rudy B. Pulmonary veno-occlusive disease: Another vascular disorder associated with human immunodeficiency virus infection? Arch Pathol Lab Med 1994; 118: 664-666.

3. Tomashefski JF, Hirsch CS. The pulmonary vascular lesions of intravenous drug abuse. Hum Pathol 1980; 11: 133-145.

4. Wagenvoort CA, Wagenvoort N, Takahashi T. Pulmonary veno-occlusive disease: involvement of pulmonary arteries and review of the literature. Hum Pathol 1985; 16 : 1033-1041.

5. Speich R, Jenni R, Opravil M, Pfab M, Russi EW. Primary pulmonary hypertension in HIV infection. Chest 1991; 100: 1268-1271.

6. Polos PG, Wolfe D, Harley RA, Strange C, Sahn SA. Pulmonary hypertension and human immunodeficiency virus infection: two reports and a review of the literature. Chest 1992; 101: 474-478.

7. Mette SA, Palevski HI, Pietra GG, et al. Primary pulmonary hypertension in association with human immunodeficiency virus infection: a possible viral etiology for some forms of hypertensive pulmonary arteriopathy. Am Rev Respir Dis 1992; 145: 1196-2000.

8. White DA, Matthay RA. Noninfectious pulmonary complications of infection with the human immunodeficiency virus. Am Rev Respir Dis 1989; 140: 1763-1787.

9. Gilroy RJ, Teague MW, Loyd JE. Pulmonary venoocclusive disease: fatal progression of pulmonary hypertension despite steroid-induced remission of interstitial pneumonitis. Am Rev Respir Dis 1991; 143: 11301133.

10. Rich S. Prostacyclin and primary pulmonary hypertension. Ann Intern Med 1994; 121: 463-464. 